\title{
GASTOS EM SAÚDE: OS FATORES QUE AGEM NA DEMANDA E NA OFERTA DOS SERVIÇOS DE SAÚDE
}

\author{
Paola Zucchi* \\ Carlos Del Nero* \\ Ana Maria Malik**
}

\begin{abstract}
RESUMO: Neste momento de crise financeira do Estado, é importante o uso adequado dos recursos econômicos disponiveis, e este trabalho objetiva estudar os fatores que determinam o aumento dos gastos em saúde; é uma revisão crítica do tema, com um levantamento sistemático das publicações dos últimos dez anos, considerando-se os principais estudiosos da disciplina da economia da saúde no Brasil e de outros países. Os fatores que agem na demanda por serviços de saúde são de natureza variada, podendo se sobrepor, o que aumenta ainda mais a demanda: necessidade sentida, fatores psicossociais, seguridade social, demografia, epidemiologia, utilização dos serviços, regulamentação e fatores culturais. Os que agem na oferta da assistência à saúde são: progresso técnico-médico, difusão da inovação e multiplicação dos centros de assistência à saúde. Os fatores da demanda não podem ser rapidamente contidos, enquanto que os de oferta são muito mais facilmentecontrolados, mas são poucos os exemplos encontrados na literatura sobre o sucesso das medidas de controle.
\end{abstract}

PALAVRAS-CHAVE: crise financeira, serviços de saúde, gastos em saúde, demanda, oferta

\footnotetext{
* Faculdade de Saúde Pública da Universidade de São Paulo

** Faculdade de Saúde Pública da Universidade de São Paulo e Escola de Administração de São Paulo da Fundação Getúlio Vargas
} 


\section{INTRODUÇÃO}

No atual momento de crise financeira do estado, torna-se importante o uso adequado dos recursos econômicos disponíveis. Gastar menos e melhor deve ser um dos objetivos a ser seguido pelo setor saúde. A reflexão sobre o tema, o estudo dos fatores que interferem no consumo de assistência à saúde, sejam do lado da oferta ou da demanda, além de outras razões importantes envolvidas no crescimento dos gastos em saúde, observados na maioria dos países ocidentais, são a proposta deste trabalho.

As razões mais comumente evocadas para explicar o aumento dos gastos em saúde são o envelhecimento das populações, a maior oferta de médicos e serviços de saúde e o progresso tecnológico. Estes fatores têm, sem dúvida, grande importância, porém não conseguem ser suficientes para explicar o aumento dos gastos em saúde.

Existe uma preocupação crescente com os fatores econômicos, que condicionam tanto a prestação de serviços de saúde como o próprio nível de saúde da população. Isto explica a inquietude dos poderes públicos em relação a um setor cujas despesas crescem a um ritmo superior ao crescimento do Produto Interno Bruto (PIB).

Encontram-se no setor saúde diversas abordagens relativas ao papel representado pelo estado e pelo mercado em seu funcionamento. Nos Estados Unidos observa-se uma liberdade relativa de fixação de preços dos serviços de saúde, com a predominância do seguro privado, privilegiando o assim chamado pensamento pró-mercado. Na Europa, notase a existência de tabelas de preços regulamentadas, além da influência exercida pelos enormes sistemas de seguridade social, predominando na economia da saúde uma perspectiva de administração pública(LABOURDETTE, 1988).

A pressão da demanda requer não só incrementos permanentes na oferta. É preciso um acesso mais equânime aos serviços para toda a população. A exigência social de maior cobertura conduz a uma atuação do governo, criando e mantendo direta ou indiretamente serviços de saúde. No Brasil, como em muitos outros países, coexistem os dois tipos de atuação, dois pesos e duas medidas: o que é válido para o setor privado não é assim no setor público e vice-versa(VIANA, ROMEU \& CASTRO, 1982).

Deixando para os cientistas políticos a polêmica decisão sobre o papel do estado na saúde, chamamos a atenção para o financiamento específico das atividades gerais desse setor econômico. A indústria da saúde pode ser considerada como um setor econômico cuja expansão é das mais rápidas. Esse aumento da "produção em saúde" relaciona-se com a melhoria da qualidade de vida e pode ser interpretado como progresso social(ILLICH, 1975). 
Ao pensarmos na alocação de recursos para o setor saúde, percebemos que é uma atividade onde a determinação dos meios e a avaliação das conseqüências são sempre complexas. Os médicos, diante do tratamento de uma doença, têm, na maioria das vezes, vários tipos de tratamentos à sua disposição. Sua escolha será feita a partir do que se tem disponível e nada nos garante que a mínima consideração da relação qualidade-preço seja determinante na decisão terapêutica final, ainda mais numa atividade ligada à vida humana, onde as preocupações de ordem ética contrapostas a possíveis análises econômicas tornamse importantes. Essas preocupações desaparecem tendo em vista as considerações sobre custos, despesas, rendimentos, sempre presentes, tanto no nível individual como no coletivo. O dilema entre a missão dos serviços de saúde e a conseqüente administração dos negócios da saúde nos faz pensar que ao lado dos objetivos humanitários, as políticas de saúde devem estimular o aumento da produção e a eficiência, nunca esquecendo porém, do paciente e da coletividade, seus objetivos últimos (MOATTIL, 1991).

Outro ponto importante que deve ser discutido é a eqüidade. O governo deve procurar diminuir as diferenças de mortalidade entre as categorias sociais, diferenças que trazem à tona a desigualdade.

A eqüidade tem sido freqüentemente associada à justiça social. Sua definição e os princípios distributivos dai decorrentes dependem do conjunto de valores sócio-econômicos predominantes na sociedade em questão.

MOONEY em 1986, sugere cinco possíveis definições de eqüidade em saúde.

A definição de equidade deve pressupor não só o sentido restrito da quantidade de recursos materiais e humanos (leitos, consultórios, médicos, enfermeiros, etc.) mas também qualidade dos serviços oferecidos.

A teoria ainda não foi capaz de definir o que viria a ser de fato a necessidade por assistência à saúde. Por mais eqüitativos que sejam a oferta e o acesso a assistência à saúde, persistirão iniquidades de resultados determinadas por desigualdades de renda, de nível educacional e, claro, de infra-estrutura sanitária(GIRALDES, 1988; JARDANOVSKI \& GUIMARÃES, 1993).

O setor saúde frustra-se quando, extrapolando sua competência de produzir serviços médicos-sanitários, tenta influir por si só nos indicadores de saúde da coletividade, sem levar em conta que a melhoria do nível de saúde de uma população só se torna permanente quando oriunda de medidas que superem as restrições impostas pelo contexto econômico e social (VIANA, ROMEU \& CASTRO, 1982). 
Nessa tentativa de proporcionar uma assistência à saúde que não frustre o setor, os países desenvolvidos confrontam-se com um aumento rápido dos gastos em saúde. É normal que se tenha procurado as causas que expliquem este aumento, entre elas o aumento da demanda por saúde assume um papel essencial.

Quando medimos a progressão das despesas de saúde em um grande número de países da O.C.D.E. (Organização de Cooperação e de Desenvolvimento Econômico), em vinte anos, a participação da saúde no Produto Interno Bruto, dobrou ou quase dobrou (LABOURDETE, 1988).

Os gastos mundiais com saúde totalizaram cerca de US\$ 1700 bilhões em 1990, que representam $8 \%$ dos recursos globais. Os países economicamente estáveis gastam cerca de US $\$ 1500$ bilhões em saúde enquanto os países em desenvolvimento gastam US $\$ 170$ bilhões. Esses números são fundamentais para nos mostrar o quão importante é entender o impacto das políticas governamentais na saúde das pessoas.

Os governos também influenciam indiretamente a saúde através de suas políticas de educação, saneamento, e outros setores, além de regular o próprio sistema de saúde e os recursos que o alimentam(WORDL DEVELOPMENT REPORT, 1993).

Tão importante quanto a magnitude do gasto com saúde é a forma de organização do sistema de saúde e suas condições de acesso.

\section{OS FATORES DE CONSUMO E DEMANDA QUE AGEM NA ASSISTÊNCIA À SAÚDE}

O crescimento dos gastos em saúde depende do mercado, ou seja, do encontro entre os que querem adquirir os bens e serviços de saúde e aqueles que os oferecem. Nas seções seguintes estudaremos os fatores envolvidos no consumo e na demanda por assistência à saúde.

\section{Os Fatores de Consumo}

Uma definição simplificada de mercado é o lugar onde se encontram, para realizar suas trocas, os que ofertam e os que demandam, ou seja os vendedores e os compradores, é a organização de ofertas e demandas, determinando, após troca de informações, a formação do preço do bem e a determinação das quantidades trocadas (SIMON, J.M.; BERTRAND, D. MICROECONOMIE, 1992). 
O consumo consiste no uso de bens ou de serviços visando a satisfação direta das necessidades. Podemos falar em consumo de bens e serviços de saúde, que trazem uma melhora do bem estar e das condições de existência de uma população.

O consumo traduz-se sob a forma de compra de bens e serviços sendo portanto, um gasto efetivamente realizado. A demanda geral por um bem reflete as intenções de compra em paralelo com os diversos níveis de preço. O consumo de saúde é um consumo final em oposição ao consumo intermediário efetuado em vista da produção dos bens (TRIOMPHE, 1975).

Em seu artigo de 1963, ARROW, refere-se a especificidade do setor de saúde em relação à grande maioria dos outros setores econômicos: "Os mecanismos habituais pelos quais o mercado assegura a qualidade dos produtos não tem grandes implicações no setor de saúde".

O setor saúde apresenta estruturas de mercado complexas e nada óbvias. Essas estruturas influenciam criticamente os padrões de atendimento médico e não podem ser ignoradas. Pelo lado da oferta, o lucro não é por si só um motivo adequado para explicar o "mercado" da saúde, como é para outros tipos de bens e serviços, dado que há um grande número de instituições públicas e privadas não lucrativas que prestam serviços de saúde. Como tais serviços não podem ter um preço "a priori" definido no mercado, torna-se difícil medir a preferência dos consumidores por eles. A própria medicina estatal, em um grande número de países desenvolvidos garante direitos ao consumo de tais serviços àqueles que não podem pagar pelos mesmos. Pelo lado da demanda, os consumidores não escolhem entre os serviços de saúde e os demais bens e serviços através de uma "racionalidade na escolha", e sim pela necessidade ou não de consumo de tais serviços. Esse consumo geralmente não é previsível e ocorre em situações de forte conteúdo emocional/psicológico. Quem vai fixar que tipos de serviços vão ser consumidos é, em última instância, o médico, aquele que faz o diagnóstico, e não o paciente(MEDICl, 1983).

O consumo de saúde é composto por basicamente três estruturas diferentes: medicamentos, honorários de médicos, dentistas e auxiliares dos serviços médicos e, finalmente, gastos em hospitalização e tratamento. Atualmente, os gastos em hospitalização e tratamento encabeçam as despesas do consumo em saúde.

O consumo de saúde não é tão sujeito às mudanças conjunturais como os outros consumos que fazem parte da rotina de cada indivíduo. É importante lembrarmos porém, que o conjunto dos gastos em saúde não é igualmente distribuído entre os consumidores. 
Duas causas distintas podem existir quando pensamos no aumento do consumo em saúde. A primeira delas é o refinamento dos diagnósticos, onde o uso cada vez mais freqüente de exames radiológicos e de análises laboratoriais é responsável pelo aumento dos gastos em saúde. Esses atos tornam cada vez mais altos os preços dos diagnósticos e consequentemente o preço de uma diária hospitalar. A segunda causa é a difusão do progresso tecnológico que é o principal elemento do incremento das despesas em saúde, que aumentam à medida que as novas técnicas são incorporadas.

Neste ponto torna-se importante falarmos de práticas que necessitam ser mudadas, como o uso indevido ou excessivo de procedimentos não necessários, agentes de aumento dos gastos em saúde.

No começo dos anos 80 o Brasil detinha um dos maiores índices de cesarianas realizadas no mundo, $31 \%$ de todos os partos hospitalares no ano de 1981 . Embora a cesariana seja uma alternativa necessária em certos casos, o seu uso indiscriminado determina gastos e impõe riscos médicos para a mãe e sua criança. $O$ custo financeiro das cesarianas desnecessárias realizadas no serviço público do Brasil foi estimado em cerca de US\$ 60 milhões anuais na década de 80.

Algumas campanhas foram feitas para educar os médicos no sentido de não indicarem cesarianas que não fossem realmente necessárias. O modo de remuneração desta prática também foi alterado para que os hospitais fossem desencorajados de fazê-la. Apesar desses esforços os índices de cesarianas continuam altos. No estado de São Paulo, durante 0 ano de 1991, 47\% dos nascimentos foram via cesariana, mantendo o risco e o custo elevados(WORDL DEVELOPMENT REPORT, 1983).

\section{Os Fatores de Demanda}

Os fatores que agem na demanda por serviços de saúde são de natureza muito variada, podendo se sobrepor, o que aumenta ainda mais a demanda.

\section{A necessidade sentida}

A tomada de consciência do estado mórbido é o primeiro elemento indispensável para a demanda por serviços de saúde. $O$ crédito dado ao sistema de saúde e a esperança de se curar usando seus serviços são igualmente necessários na decisão de querer consumir.

Atualmente a tomada de consciência por parte dos indivíduos com relação ao seu próprio corpo tem aumentado. $O$ indivíduo está mais atento aos riscos de doença. $O$ 
conhecimento dos sintomas por parte da população também tem aumentado. $O$ crédito dado ao sistema de saúde é evidente: espera-se a cura de uma doença ou pelos menos o desaparecimento dos sintomas.

O médico deve curar. Atualmente esta atitude é bastante diferente daquela de há um século atrás onde o aspecto mágico do médico predominava sobre a natureza científica dos cuidados dispensados aos pacientes.

A necessidade por assistência aparece logo que saibamos, esperemos ou acreditemos que a ciência médica possa corrigir uma situação julgada anormal, ou em relação a outras ou em relação a um estado anterior. Esta necessidade é essencialmente subjetiva. Ela depende de alguns fatores: da instalação de um problema de saúde específico, da oferta de assistência à saúde, como técnicas oferecidas e sua proximidade, e do que se espera dos serviços oferecidos (BERTRAND, 1991).

\section{Os fatores psicossociais}

O sexo feminino parece ser mais consumidor de assistência à saúde que o sexo masculino, durante toda a duração da vida. As curvas, em função da idade, indicam que essa diferença é mais importante nos momentos em que os problemas gineco-obstétricos são mais freqüentes (gravidez, menopausa, etc.). Esta diferença entre os dois sexos fica mais evidente com o avançar da idade. Se a população considerada, compreende um número maior de mulheres idosas, isso pode ser a explicação das diferenças de procura dos serviços de saúde entre populações (McPHERSON, 1990).

Quando analisamos os índices de mortalidade masculina, observamos que esses índices são maiores quando comparados a mortalidade feminina. Algumas explicações foram dadas para explicar este fato, como causas ligadas ao ambiente, certos autores invocam as conseqüências da civilização industrial e urbana: condições de vida cada vez mais estressantes, poluição, falta de exercício físico, tensão psicológica, à qual os homens estariam mais expostos, mas, a partir da tomada de posição da mulher na sociedade em termos e posições semelhantes às do homem, começa a se notar um aumento da morbimortalidade feminina nas doenças que antes atingiam predominantemente os homens como as doenças cardiovasculares, os acidentes de trânsito e as conseqüências da violência urbana. O consumo de tabaco também pode ser origem dos índices maiores de mortalidade masculina (TRIOMPHE, 1975).

O consumo de assistência à saúde também aumenta com o nível de instrução, talvez como conseqüência do melhor conhecimento dos sintomas bem como do risco da 
gravidade dos mesmos, estando este fato diretamente relacionado com o mais adequado conhecimento sobre o próprio corpo por parte do indivíduo melhor instruído.

Nunca é demais valorizar a importância dos fatores sócio-econômicos no condicionamento da saúde ou da doença. Se os ambientes físico e biológico albergam fatores ainda não controlados, contribuintes para a geração de enfermidades, é também verdade que um bom nível sócio-econômico como que neutraliza os fatores ambientais adversos. A recíproca é verdadeira. Um baixo nível sócio-econômico está sempre associado a um baixo padrão do nível de saúde, assim mostram os fatos e as estatísticas.

É importante analisarmos a existência ou não de uma seguridade social que permita o acesso da população ao atendimento de saúde. Nesses casos, haverá uma relação muito mais positiva entre renda e consumo, quando esta proteção não for abrangente ou quando os serviços pagos pelo paciente/terceiro não forem reembolsados.

A localização geográfica da população é também importante já que se sabe que a população urbana consome mais que a população rural, até mesmo pela facilidade do acesso.

O tamanho da família e a categoria sócio-profissional também são fatores determinantes de desigualdades na demanda por assistência à saúde.

Além dos problemas de saúde cuja existência está associada a agentes dos meios físico e biológico, existem outros como a fome, decorrente da desigual distribuição de renda; as doenças ocupacionais, decorrentes das más condições de trabalho; a delinqüência, o suicídio, o alcoolismo, o abuso de drogas e outros decorrentes, de uma forma geral, de estados em que prevalece a desestruturação biopsicossocial, que de uma maneira ou de outra acabam por determinar o aumento da demanda por assistência à saúde.

Antes da revolução industrial, pensava-se que as influências ambientais/climáticas eram as mais importantes para determinar a ocorrência de doenças. Desde meados do século XVIII, na Inglaterra e posteriormente na França e Alemanha, com a mudança para uma economia predominantemente industrial, sobressaiu a importância do ambiente sócioeconômico na distribuição das doenças. Isso torna-se evidente quando observamos que as taxas de morbidade e mortalidade dependem das condições de vida das diferentes classes da população que determinam consumos de assistência à saúde diversos (ALMEIDA Fo. \& ROUQUAYROL, 1990). 


\section{A seguridade social}

A seguridade social acentua o consumo porque ela o torna menos oneroso aos indivíduos e famílias.

No Brasil, observa-se a universalização do atendimento que, inserida na Constituição Federal de 1988, garante a todos os brasileiros o direito a saúde, ou pelo menos o acesso aos serviços de saúde. Este fato independe da contribuição fiscal por parte da população. Podemos verificar, dessa maneira, o ônus que a universalização do atendimento proporciona ao estado que, na mesma constituição tem o dever de prestar esse atendimento. Ao mesmo tempo, o princípio da seguridade social é compartilhar com a sociedade custos que um indivíduo e/ou família não teriam condições de suportar. A dificuldade se encontra em discriminar quais serviços serão parte do esquema da seguridade social. Certamente, é um fator que age na demanda por serviços.

\section{A demografia}

A cada ano a população do mundo aumenta cerca de 80 milhões de pessoas, porém em alguns países da Europa, este crescimento já não ocorre e espera-se para o final do século 21 , uma diminuição do número de europeus. Observa-se nesses países que a taxa de natalidade caiu abaixo da taxa de mortalidade, não assegurando mais a renovação da população. Por outro lado, espera-se um aumento importante na população da América do Sul, África e Ásia (TRIOMPHE, 1975). Com este rápido perfil da evolução demográfica da população mundial, podemos estimar um aumento da demanda em virtude do aumento da população em algumas regiões geográficas e mesmo de seu envelhecimento, mais generalizado no planeta.

As curvas de consumo de saúde em função da idade mostram um aumento considerável e contínuo, a partir de quarenta anos de idade.

Outro fator importante que colabora para o aumento dos gastos com saúde é a evolução da esperança de vida da população. $O$ envelhecimento da população sugere um aumento dos gastos para a manutenção, prevenção e tratamento da saúde dessas pessoas.

Do começo do século aos dias de hoje, a esperança de vida ao nascer aumentou consideravelmente nos países desenvolvidos e subdesenvolvidos, sendo este fenômeno mais importante no sexo feminino que no masculino. Podemos ainda observar, que há diferenças relacionadas com a classe social onde, pessoas de nível sócio-econômico mais elevado têm uma esperança de vida maior que pessoas de nível sócio-econômico inferior. 


\section{A epidemiologia}

Variações quanto à incidência das doenças podem existir principalmente entre países desenvolvidos e em desenvolvimento, dificultando as comparações e podem assim, explicar as diferenças existentes entre as populações estudadas com relação a procura de assistência à saúde.

As doenças características de países desenvolvidos, com populações de esperança de vida mais elevadas, implicam em tratamentos onerosos e longos, e às vezes, grandes períodos de hospitalização em centros super-especializados.

O Brasil apresenta características de todos os modelos epidemiológicos, sendo evidente o "período de transição epidemiológica" que atravessa, apresentando dessa maneira doenças características de países subdesenvolvidos, como diarréia e subnutrição, e outras doenças, típicas de países com populações mais velhas, como as crônicas e degenerativas. A abordagem desses dois grupos de doenças requer maior esforço por parte dos programas de saúde e, consequentemente, maior despesa.

Nos EUA, o ponto de mudança das doenças crônicas e infecciosas ocorreu por volta de 1925. Observa-se que o número de mortes por doenças infecciosas declinou, neste país, $96 \%$ no período de 1900 a 1970. Não conseguimos um dado semelhante no Brasil, apesar dos indicadores de causas de óbitos mostrarem declínio das doenças infectocontagiosas, predominando atualmente as causas cardiovasculares.

Esta transição representa uma mudança nos padrões de doença. O motivo encontrase na mudança de uma sociedade agrária para uma sociedade industrializada. As doenças que atingem um determinado segmento de uma cultura variam de acordo com as condições físicas e sociais, características da sociedade da época.

A erradicação das doenças infecto-contagiosas, deixa lugar para as doenças crônicas para as quais o paliativo é a regra e o tratamento etiológico é ainda desconhecido.

A importância das "doenças sociais" como drogas, álcool e fumo, e o aparecimento de patologias novas como a AIDS, encarecem cada vez mais a assistência à saúde.

\section{A utilização dos serviços de saúde}

O conjunto de interações entre os profissionais de saúde e seus clientes ocorre dentro de um ambiente organizacional que é rodeado e penetrado por traços sociais e 
culturais. A utilização dos serviços de saúde é influenciada por fatores socioculturais e organizacionais além de fatores relacionados com o consumidor e com o prestador de serviços.

As determinantes socioculturais da utilização dos serviços de saúde incluem tecnologia e valores sociais. A tecnologia é considerada como um fator sociocultural, e não organizacional que influencia a utilização dos serviços. Em alguns casos, ela reduz a utilização, reduzindo os níveis de doença ou a necessidade de cuidados médicos. Valores sociais também influenciam a utilização de serviços de saúde. Um exemplo disso é o fato de em São Paulo a grande maioria dos partos serem hospitalares.

Outra categoria de determinantes da utilização dos serviços de saúde inclui as estruturas e processos que constituem a organização dos serviços médicos e que circundam e influenciam intimamente o processo assistencial. Esses fatores organizacionais envolvem alguns aspectos: a disponibilidade de recursos, a acessibilidade geográfica, a acessibilidade social, as características de estrutura e os processos de prestação da assistência à saúde.

Podemos observar que a utilização dos serviços de saúde é determinada pela interação entre os consumidores e as fontes ou prestadores de assistência à saúde num ambiente social e organizacional. Muitas características dos consumidores que envolvem fatores sócio-demográficos e sócio-psicológicos estão relacionados à utilização de serviços (DEVER, 1988).

\section{A regulamentação}

É importante também mencionarmos que a Lei Orgânica da Saúde estabelece como um de seus princípios fundamentais a descentralização política e administrativa, enfatizando a municipalização.

A Lei define as competências e atribuições de cada esfera de governo, mudando a estrutura de poder em favor das esferas locais e regulamenta as transferências financeiras, explicitando os critérios para a sua distribuição (Artigo 35): perfil demográfico, perfil epidemiológico, características qualitativas e quantitativas da rede de saúde, desempenho técnico, econômico e financeiro, nível de participação do setor saúde nos orçamentos estaduais e municipais, previsão do plano qüinqüenal de investimentos, ressarcimento do atendimento a serviços prestados a outras esferas de governo.

No parágrafo primeiro do mesmo artigo acrescenta-se que metade dos recursos destinados a estados e municípios serão distribuídos em base populacional (PORTO, 1991). 


\section{Os fatores culturais}

A cultura de uma população pode também ser um fator determinante de demanda. Certas coletividades repelem certas práticas médicas mais que as outras, mesmo quando há acesso e ou indicação de uso. Isso pode ser explicado pelo conhecimento médico dominante ou pelas preferências dos doentes, herdeiros de costumes ou de tradições antigas (MEPHERSON, 1990).

Para uma parte da população, estar doente não significa um evento exclusivamente biológico, projetando-se no efeito mais dramático, que produz a incapacidade de trabalhar e a conseqüente ameaça à subsistência familiar. Nessas camadas da sociedade a doença não é considerada um evento exclusivamente biológico, tendendo a ser percebida somente quando houvesse uma incapacitação de performance social, representada principalmente pelo trabalho. Um indivíduo ao mostrar-se disposto e com capacidade para trabalhar é considerado saudável. A saúde é utilizada para o benefício de propósitos sociais; ela é alienada do indivíduo (QUEIROZ, 1991). Nas camadas sociais superiores acontece o contrário.

Nesse grupo social é a mulher, mãe e dona de casa que mais percebe sintomas de doenças já que o homem permanece distante, no trabalho. Esse grupo mostra uma tendência a fazer uso de medicina caseira e medicina religiosa, usando para tal ervas medicinais e benzeduras.

A oferta de serviços de saúde oficiais para esse grupo compreende, basicamente, a rede básica de serviços públicos de saúde, os farmacêuticos, a medicina conveniada $e$ parte da medicina privada, envolvendo agentes tais como médicos, enfermeiras, atendentes de enfermagem e práticos de farmácia.

Um estudo realizado em Paulínia por QUEIROZ (1993), aponta a importância das farmácias do município como instâncias de assistência médica prestada à população, oferecendo consultas médicas como uma questão humanitária da qual não poderiam se esquivar diante da ineficácia dos serviços públicos e do sofrimento dos pacientes.

Num mercado capitalista, o consumo em saúde decorre de um complexo conjunto de elementos de decisão, valores, representações, padrões culturais e práticas individuais, familiares e de classe social. As estratégias de consumo utilizam-se de elementos de diferentes sistemas de cura e de diferentes agentes e situações dentro de cada sistema, que, por sua vez, são influenciados pelo padrão de desenvolvimento econômico e social vigente na sociedade. Fatores gerais, tais como as condições de produção da oferta, o 
padrão de distribuição de renda, as políticas governamentais e a pertinência a classes e estratos sociais, imprimem uma influência fundamental na organização do consumo (QUEIROZ, 1993).

\section{OS FATORES QUE AGEM NA OFERTA ASSISTÊNCIA À SAÚDE}

A produção é a forma de atividade econômica orientada para o fornecimento de bens e serviços destinados a satisfazer necessidades individuais e coletivas. A produção da saúde consiste no conjunto de bens e serviços destinados ao diagnóstico e tratamento das afeções patológicas dos indivíduos. Deve-se também acrescentar uma parte de serviços e bens visando a prevenção das doenças.

As unidades de produção médica são muito variadas: instituições públicas (hospitais, centros de saúde), instituições privadas, consultórios médicos que asseguram com o pessoal do setor a produção de saúde utilizando as técnicas existentes.

Consideram-se serviços de saúde os que tratam do exercício legitimado da medicina, da odontologia e outras atividades cujo fim explícito é preservar ou restaurar a saúde da população. Não estão compreendidas nesta categoria: a "medicina popular" (não legitimada); a indústria produtora de "bens de saúde", como a farmacêutica, de equipamento hospitalar etc.; atividades que, embora influam fortemente sobre a situação de saúde da população, como por exemplo os serviços de saneamento, não fazem parte dos serviços de saúde propriamente ditos (SINGER, CAMPOS \& OLIVEIRA, 1988).

A oferta de serviços de saúde cresceu consideravelmente nos países desenvolvidos nos últimos trinta anos, pela extensão da política social e através de uma pressão de demanda por assistência à saúde exercida pela população. A oferta se multiplicou por dois ou mesmo três, nesses países e isso está relacionado à influência de três fatores principais: o progresso técnico-médico, a difusão das inovações e a multiplicidade dos centros de assistência à saúde.

\section{O progresso técnico-médico}

A origem das inovações em medicina provém de várias fontes. A transferência de tecnologia vinda de outros setores da economia, industrial por exemplo, mudanças qualitativas de materiais anteriores permitindo novas aplicações ou o surgimento de técnicas mais precisas ou mais seguras no diagnóstico das doenças, ou mesmo as adaptações de técnicas antigas para novas necessidades. 
A pesquisa das doenças permitiu progressos importantes nas áreas de diagnóstico por imagem e nas áreas de laboratório. A radiologia clássica encontra na ultra-sonografia, na tomografia ou na ressonância magnética, complementos indispensáveis. A tomografia de crânio, por exemplo, substituiu exames dolorosos, traumáticos e com algum risco como a arteriografia cerebral ou a ventriculografia.

Os exames de tomografia foram objeto de uma demanda crescente, potencialmente já existente. A extensão da demanda foi seguida pela oferta de cuidados médicos. Os aparelhos de análises clínicas automatizados que não necessitam mais que uma manipulação para obter 6, 12 ou mais tipos de exames. Esta facilidade na análise bioquímica determinou uma modificação na demanda de alguns serviços hospitalares, o médico não escolhe mais um exame e sim pede um perfil.

A indústria farmacêutica participa desta evolução tecnológica com a criação de novas moléculas, permitindo uma melhora qualitativa da vida e mesmo uma cura real para a maior parte dos estados patológicos, tendo sem dúvida uma influência moderada sobre os gastos com saúde.

\section{A difusão da inovação}

A inovação técnica de alto nível aparece inicialmente nos hospitais mais importantes. Com este contato formam-se especialistas. O número destes especialistas sendo superior à capacidade do hospital propicia a migração para outros hospitais menos equipados. Uma certa banalização e uma descentralização da técnica aparece, a obsolescência é rápida, novos meios técnicos são criados e esse ciclo continua.

Nesse ciclo existem duas possibilidades: ou o material é extremamente caro para a compra e utilização e para assegurar sua rentabilidade é necessário implantá-lo somente em alguns grandes centros com a certeza de um uso adequado, ou o material vulgariza-se rapidamente, seu preço baixa e uma descentralização da decisão médica pode ter lugar. Portanto, de um lado a inovação determina uma centralização médica, e por outro essa inovação permite uma autonomia de decisão das unidades de saúde menores.

A especialização dos médicos aumentou nos últimos anos. Esta maior especialização determina uma modificação na produção médica. Os atos médicos mais banais, consultas e visitas, diminuem comparativamente aos atos mais técnicos, de especialidades, cirúrgicos ou radiológicos. Este aumento pode ser justificado mas é importante que os recursos sejam mais racionalmente usados. 


\section{A multiplicação dos centros de assistência a saúde}

Esta multiplicação induz demanda. É clássico dizer-se em economia da saúde que a oferta cria sua própria demanda, a conhecida "Lei de Roemer". A mudança da qualidade da oferta pode também originar as modificações na demanda. Neste sentido a humanização do hospital pode ter tido um papel importante na modificação da demanda por serviços de saúde. É certo que o aparecimento de novos equipamentos facilita o acesso aos serviços de saúde a uma camada da população até o momento distanciada dos centros de saúde. Trata-se do desaparecimento de distâncias entre o consumidor e o lugar do consumo. $O$ surgimento de novos leitos determina a entrada no hospital de doentes que anteriormente seriam tratados em outras estruturas de serviços de saúde, consultórios, por exemplo (BERTRAND, 1992).

Sejam quais forem as formas de prestação, os serviços de saúde terão que ser pagos. As configurações de mercado e a estrutura de preços, prevalentes terão conseqüências sobre o sistema de saúde. Existe um mercado, distribuindo renda, gerando incentivos e até mesmo distorcendo as intenções dos planejadores ou administradores.

As forças do mercado podem prevalecer sobre as intenções dos administradores, gerando padrões de serviços e níveis de oferta/demanda discrepantes dos planos iniciais. No Brasil, por exemplo, enfermeiros não tratam diretamente dos pacientes e trabalham como administradores de enfermagem. Dessa maneira os pacientes são tratados por pessoal de nível técnico ou inferior.

O corporativismo e a cartelização, podem restringir o livre jogo das forças de mercado, surgindo outras formas de ajustamentos de preços em decorrência das novas formas de organização dos serviços médicos. Com o crescimento da oferta de médicos no Brasil, o preço médio da consulta médica deveria ter diminuído, porém, a Associação Médica Brasileira, AMB, estabeleceu um valor mínimo para as consultas e procedimentos médicos. Esse mínimo ainda não é respeitado principalmente pelas empresas de medicina de grupo que, na tentativa de lucros cada vez maiores, impõem ao médico tabelas desatualizadas ou com valores menores daqueles preconizados pela AMB. Um dos fatores mais importantes para impedir a redução dos preços das consultas é o Código de Ética Médica, que condena a concorrência comercial entre profissionais. Mais ainda, a noção equivocada difundida entre os consumidores, de que a qualidade da assistência médica é medida pelo preço da consulta, pode também impedir a sua redução.

Pressão dos pares, manipulação corporativista e ignorância do consumidor, provavelmente contribuem para essa inelasticidade dos preços. Mas, permanece o fato de 
tratar-se de um mercado de livre entrada a todos os que possuem diploma de médico.

A concentração das escolas médicas em grandes centros foi tolerada por acharem alguns que haveria migração para áreas menos populosas, devido à concorrência resultante da concentração de profissionais. Isso não aconteceu no Brasil. Talvez os diferenciais de renda não sejam significativos devido à maior riqueza dos grandes centros e por uma expansão na demanda de médicos induzida pela oferta. Talvez a divisão da medicina, em dezenas de especialidades e sub-especialidades, seria um obstáculo ao exercício profissional em áreas desprovidas de recursos para complementação diagnóstica e terapêutica (VIANA, ROMEU \& CASTRO, 1982).

Os recursos disponíveis tem um efeito marcante sobre as decisões clínicas. Certas opções são eliminadas quando da não disponibilidade dos recursos necessários no momento, ou quando um racionamento se impõe em razão de uma hierarquia de prioridades na mobilização dos recursos disponíveis.

Outro fator importante, é o modo de admissão do doente ao hospital. Quando o sistema de saúde baseia-se num princípio de hierarquia das decisões, a hospitalização é resultado de várias filtragens. Por exemplo, no Reino Unido, os doentes devem inicialmente obter a permissão do generalista, que pode decidir encaminhá-los para um nível hierarquicamente superior onde a decisão da necessidade de uma internação hospitalar será tomada. Como essas decisões são sujeitas a influências exógenas diversas, o resultado poderia ser sistematicamente diferente daquele obtido, se os mesmos doentes fossem submetidos diretamente a opinião de um especialista.

A fórmula existente nos Estados Unidos permite consultar uma segunda opinião. Quando este tipo de procedimento é rotineiro podemos esperar por dúvidas de diagnósticos e uma taxa de atos cirúrgicos menor. Quando não é praticada, essas taxas podem ser mais elevadas. Em ambos os casos, as taxas não serão apropriadas, mas a primeira opção deverá pesar menos financeiramente.

Em certos países, a assistência primária à saúde é mais importante que em outros. Quando os sistemas de saúde são submetidos a certas dificuldades, os usuários desencorajam-se a procurar os serviços de saúde. Sob esse ponto de vista, a disponibilidade de recursos exerce um efeito restritivo não permitindo certas iniciativas, mas também, tem um efeito indireto de dissuadir o doente a consultar ou modificar as decisões clínicas. Quando o volume de recursos disponiveis é mais importante, podemos ter um efeito direto de incitação à consulta (McPHERSON, 1990). 


\section{DISCUSSÃOE CONCLUSÃO}

A maioria dos países desenvolvidos apresentou até o começo dos anos 1970 uma expansão considerável dos gastos em saúde. Esta evolução correspondeu a um período de forte expansão econômica e de progresso social, num contexto político onde as reformas sociais caminham lado a lado com a concessão de benefícios aos trabalhadores, entre os quais, acesso aos serviços de saúde.

Esta fase de expansão foi caracterizada pelo surgimento de fatores de ordens diversa. A demografia, que foi modificada pelo aumento da população, da esperança de vida e pela evolução da estrutura etária da população, o que levou ao seu envelhecimento; o progresso técnico e científico que permitiu uma grande melhora dos meios diagnósticos e terapêuticos, mas também um aumento dos custos; a medicalização dos sistemas sociais, através da maior exposição das pessoas a informação sobre saúde/doença, nem sempre verídicas. Testes de prevenção de câncer, por exemplo, tornaram-se obrigatórios antes mesmo de comparada sua eficácia como programa de saúde pública. Outro exemplo importante é o caso da cesariana, adotado pelas mulheres como mais adequado que o parto normal; a diminuição do nível de tolerância das pessoas com relação aos inconvenientes que podem estar relacionados com a doença; a necessidade sentida, a tomada de consciência do estado mórbido; o aumento do número efetivo de médicos; a aceleração de certas estruturas pesadas dos sistemas de saúde; o aumento dos preços dos bens e serviços oferecidos; aumento do número de procedimentos consumidos; fatores de mercado e surgimento de novos bens; fatores psicossociais; fatores ligados à seguridade social e a gratuidade da assistência à saúde; fatores epidemiológicos; fatores relacionados a utilização dos serviços de saúde; fatores de regulamentação e fatores culturais.

Os fatores de demanda não podem ser rapidamente controlados, dependendo muito do consumidor ou da proteção social. Contrariamente, os fatores de oferta são muito mais facilmente controlados, com a ajuda de normas de instalação para equipamentos pesados, dos orçamentos hospitalares, ou do controle do número de profissionais de saúde formados. Apesar disso, poucos são os exemplos encontrados na literatura sobre o sucesso dessas medidas de controle. No Brasil, tentativas semelhantes naufragaram principalmente devido às dificuldades gerenciais e de financiamento do setor.

Os governos interrogam-se sobre a eficácia dos gastos crescentes em saúde. Apesar de atualmente existir essa discussão em termos de política social, não percebemos o alívio 
dessa situação devido a complicadores como, a incidência de novas doenças, como a síndrome da imunodeficiência adquirida (AIDS), novas técnicas, como os transplantes de órgãos, ou o progresso tecnológico incorporado aos meios de diagnóstico e às terapêuticas medicamentosas, cada vez mais complexas.

Em matéria de serviços médicos, os próximos anos deverão trazer um questionamento constante. É muito provável que novas técnicas médicas não serão mais universalmente adotadas antes de uma avaliação custo-benefício. Tentar-se-á chegar cada vez mais, a um processo de racionalização. Mas existem dificuldades entre os prestadores de entender o que é racionalização para um serviço de saúde. É preciso não confundir racionalização com racionamento e estar absolutamente certo de que o público não será privado de um serviço eficiente.

A solução desse dilema da racionalização dos gastos, depara-se com dois obstáculos. O primeiro deles refere-se à profissão médica, que tem a responsabilidade da decisão e o poder de decidir. Além disso o médico tem um papel muitas vezes conflituoso de conselheiro de seu paciente e de vendedor de serviços. O segundo obstáculo, esse é de fato um obstáculo real, cabe à dificuldade de responder a um número significativo de questões importantes, como por exemplo a necessidade ou não de se realizar exames subsidiários para elucidação do diagnóstico, qual é o tratamento mais indicado, etc.

Se queremos limitar os recursos destinados à prestação de serviços adequados, é preciso definir quais serão os níveis de assistência à saúde praticados. Mas em relação a isso são múltiplas as opiniões, mesmo as mais autorizadas. Em muitos casos, os médicos divergem sobre a natureza do melhor tratamento. Isto sem considerar a influência da relação médico-paciente, que muitas vezes passa do individual ao coletivo.

$\mathrm{Na}$ área médica, a tomada de decisão é freqüentemente complexa e depende de considerações científicas, de desejos do doente, de preferências do médico e de influências exteriores de naturezas diversas, onde algumas, como a família ou a sociedade, não tem nenhuma relação com a decisão a ser tomada (McPHERSON, 1990).

Poderiamos sintetizar o aumento das despesas com a saúde em pelo menos quatro grandes causas:

A primeira causa é o aumento dos preços dos bens e serviços oferecidos. Trata-se de um efeito preço, sem um acréscimo simultâneo da qualidade ou da quantidade dos serviços oferecidos mas que resulta do aumento do preço unitário dessas prestações de serviço. Em parte este efeito é função da inflação. Entre outros fatores contributivos estão a 
demanda estimulada por novos serviços e tecnologia; pela relação de "agente" existente entre médico e pacientes; e a qualidade do produto oferecido.

A segunda causa é o aumento do número de procedimentos consumidos, em razão do aumento demográfico da população: neste caso o número de bens e serviços por habitante ficaria idêntico. Essa segunda causa é mínima, ao menos no mundo desenvolvido, sendo talvez mais importante nos países em desenvolvimento com populações ainda em crescimento.

A terceira causa depende do mercado, ou seja do encontro daqueles que desejam adquirir bens e serviços de saúde e daqueles que os oferecem. Não é simplesmente um movimento mecânico econômico e demográfico, mas é a conseqüência de fatores inerentes ao sistema de saúde.

Nesta terceira causa, podemos ver os fatores que atuam sobre a demanda, que aumentam o desejo de consumir serviços de saúde por parte dos indivíduos, e fatores que atuam na oferta, propondo cuidados mais importantes, mais diversificados e melhor distribuídos geograficamente. Certamente é um pouco artificial separar os dois fatores, já que eles estão estreitamente ligados, e a demanda só pode ser satisfeita se houver oferta.

A quarta e última causa é o surgimento de novos bens, novas tecnologias, novos medicamentos, etc. É decorrência natural do desenvolvimento da área.

Assim, o refinamento dos meios diagnósticos, induzindo um uso cada vez mais freqüente de exames radiológicos e análises laboratoriais é também responsável pela alta taxa de crescimento dos gastos em saúde. Essas ações encarecem o preço dos diagnósticos e consequentemente os preços das internações hospitalares.

Cada descoberta científica, cada nova técnica aplicada, permite ao médico cuidar melhor e, mais freqüentemente, curar. Isto amplia cada vez mais o campo da medicina; paradoxalmente, o progresso da medicina aumenta o número de doentes.

A difusão acelerada das informações sobre o progresso da medicina aumenta consideravelmente o desejo de todos de suprimir seus sofrimentos e curar suas doenças. Os pacientes se acham no direito de serem submetidos a exames novos e caros, mesmo sem indicação médica. Alguns até exigem de seu médico a realização de certos exames/ terapêuticas, dependendo de cada profissional desenvolver habilidade de lidar com as expectativas de seu cliente. 
Mas certos tratamentos, como transplantes ou diálises, são ainda muito caros para que um grande número de doentes se beneficie desses tipos de tratamento (TRIOMPHE, 1975).

As questões do controle das despesas de saúde são de duas naturezas. A primeira é normativa: por exemplo, a que nível devem se situar as despesas de saúde e qual deve ser sua taxa de crescimento? Para responder a esta questão, dentro de uma ótica de economia de bem estar, é preciso definir o valor dos resultados obtidos pelos serviços de saúde e sua relação com o valor do que foi sacrificado. As outras, são de ordem mais concreta: por exemplo, considerando a tecnologia disponível, qual é o montante de recursos necessários para obter um volume dado de serviços prestados.

Podemos analisar essas questões tanto no plano microeconômico como no plano macroeconômico.

A análise microeconômica nos leva às relações custo-benefício, custo-eficácia, custoutilidade. Este tipo de análise permite, por exemplo, uma comparação do custo-benefício de diferentes políticas a fim de que seja estabelecida a melhor combinação de medidas bem como o interesse de um aumento nas despesas.

A análise macroeconômica estuda as despesas totais: sua parte no produto interno bruto (PIB), sua composição principal e seus determinantes. Este tipo de abordagem dá origem a comparações internacionais de gastos em saúde. Além disso, estudam-se séries históricas regionais ou por países, na tentativa de demostrar a prioridade e a importância relativa da saúde como questão social.

Não é possível afirmar que um gasto é mais elevado ou menos importante que o outro; são comparações evidentemente difíceis, já que apelam a julgamentos de valor sobre o que é interessante ou não. A única maneira de compararmos essas despesas é através de uma análise das vantagens obtidas ou daquelas que foram sacrificadas (CULYER, 1990).

O controle de custos pode ser uma das soluções para o sistema de saúde e um conceito chave que devemos absorver na tentativa de reduzir orçamentos e frear 0 crescimento da demanda por serviços de saúde.

Muitos profissionais preocupam-se com a avaliação dos gastos em saúde, um exercício que implícita ou explicitamente relaciona-se com a racionalização da assistência à saúde, isto é, decidindo que demanda deve ser atendida, retardada (lista de espera) ou 
não atendida. Todavia, a análise dos custos pode ajudar a entender como aumentar a demanda por assistência à saúde, com recursos finitos, e identificar qual abordagem é mais custo-efetiva, isto é, qual abordagem pode, conseguindo seus objetivos específicos, custar menos.

Nos países em desenvolvimento, toda essa situação é mais grave, pois um país com recursos escassos não poderia gastá-los mal. Daí as iniciativas de alguns governos de fazer o usuário coparticipar com uma parcela dos gastos.

Nessa conjuntura, estudos de economia da saúde têm demonstrado como os fatores financeiros influem na escolha dos prestadores de serviços de saúde nos países menos desenvolvidos. Os estudos de demanda propõem que os serviços de saúde sejam avaliados em função de sua contribuição à melhoria do nível de saúde e não pelo seu valor intrínseco. Esses serviços, combinados com vários determinantes intermediários da saúde, como a higiene do meio e a nutrição, têm repercussões diretas sobre o estado de saúde. Essa função é qualificada como função de produção sanitária. Os usuários procuram retirar um máximo de bem estar das prestações sanitárias nos limites de um orçamento dado e das técnicas de produção existentes. Os estudos relativos à demanda raramente abordam o papel das técnicas de produção sanitária na estimativa dos determinantes de uso dos serviços de saúde.

Teoricamente, o preço que os usuários estão dispostos a pagar por um serviço de saúde determinado depende da produtividade marginal relativa e dos preços relativos da assistência à saúde e de outros elementos (LEPELTIER, 1989; WORLD DEVELOPMENT REPORT, 1993). O preço de inclusão de dependentes, a comparação de preços entre distintos planos de saúde, a existência de serviços especializados, afetam o preço final para o usuário bem como sua decisão de gasto. Quando isso acontece o usuário decide gastar com sua saúde apenas um certo montante. Por outro lado, ao delegar sua decisão de gasto a um profissional de saúde, o usuário também perde o controle que o fez decidir em primeiro lugar por determinado plano de saúde.

Quando pensamos nas necessidades de assistência médica, devemos concluir que elas não poderão ser satisfeitas a não ser com a ajuda de meios ainda mais caros que os que são atualmente utilizados. Devemos ainda lembrar que o total de gastos não é igualmente repartido entre os consumidores.

Podemos, sem dúvida, reduzir os gastos em saúde. Precisamos, então, começar a fazê-lo, mas isso provavelmente será difícil, limitado e insuficiente. É preciso sobretudo diminuir o custo da assistência medica. Como soma dos custos das intervenções médicas 
e das prescrições que elas induzem, é o ato médico de base que está em questão, e é sobre ele que devemos agir.

Oferecer uma assistência à saúde custo-efetiva, frente às inovações da tecnologia não basta. É preciso também introduzir um processo racional e sobretudo bom senso no seu desempenho diário. Aqui surgem tanto obstáculos inerentes à prática médica atual "internogramas" - ou seja, uma tendência exagerada de busca por diagnósticos mesmo na ausência de sintomas. Por outro lado, a própria expectativa do paciente e do meio social exigindo uma receita, um medicamento, um exame, enfim um "gesto médico". Neste campo, muita coisa deve ser mudada, devendo ser objetivo de pesquisa ulterior.

O processo médico moderno, que devemos formalizar e difundir, deve impor a reflexão, antes de se prescrever um exame ou um tratamento, das conseqüências práticas deste ou daquele resultado. Isto torna-se ainda mais fundamental em sociedades como a nossa, que importam um modelo médico específico ignorando outras práticas curativas informais prevalentes na comunidade.

Fazer uma medicina de qualidade e ao mesmo tempo custo-efetiva impõe uma nova postura profissional. É mais fácil munir-se de exames subsidiários que atenuam as responsabilidades e prescrever sem reflexão tratamentos que dispensem explicações. É necessário e imprescindível motivar os médicos para iniciarmos um controle dos gastos em saúde. A inutilidade de certos serviços não é evidente sobretudo para os leigos. A lei do mercado nos habitua a admitir que há, em geral, uma relação direta entre a qualidade e o custo e que o mais caro é necessariamente o melhor. No entanto, no domínio da saúde essa afirmação não é verdadeira: a boa medicina não é necessariamente cara, a medicina cara não é necessariamente boa.

Agindo sobre essa prática, será possível, teoricamente, moderar os gastos em saúde sem alterar o serviço esperado (ZUCHI, 1996; ZUCHI, DELNERO \& MALIK, 1998).

\section{REFERÊNCIAS BIBLIOGRÁFICAS}

ALMEIDA FILHO, N.; ROUQUAYROL, M.Z. Introdução a epidemiologia moderna. Rio de Janeiro, Apce-ABRASCO, 1990.

ARROW, K. Uncertainty and the welfare economics of medical care. The american economic review, 5:941-73, 1963. 
BERTRAND, D. Economie de la santé. Paris, Université Paris VII, 1992.

BERTRAND, D. Lexique socio-economique utilise en santé-publique. Paris, Université Paris VII, 1991.

CULYER, A.J. La maîtrise des dépenses de santé en Europe. OCDE Etudes de politique sociale, 7:17-30, 1990.

DEVER, G.E.A. A epidemiologia da utilização dos serviços de saúde. A epidemiologia na administração dos serviços de saúde. São Paulo, Pioneira, 1988. p.211-36.

GIRALDES, M.R. Eqüidade e despesa em saúde. Estudos de Economia, 8:365-88, 1988.

JARDANOVSKI, E.; GUIMARÃES, P.C.V. O desafio da eqüidade no setor saúde. Rev. Administração de Empresas, 33(3):38-51, 1993.

ILLICH, I. Némésis médicale. L'expropriation de la santé, Paris, Seuil, 1975.

LABOURDETTE, A. Economie de La santé. Paris, PUF, 1988.

LEPELTIER P. L'entreprise Santé au coeur de l'économie immatérielle. In: LAUNOIS R. Des remèdes pour la santé. Paris, Masson, 1989.

MCPHERSON, P. Variations entre pays des pratiques médicales. OCDE Etudes de politique sociale, 7:17-30, 1990.

MEDICl, A. As contribuições da economia à pesquisa em saúde. IPEA, MIMEO, 1983.

MOATTI, J.P. Ethique médicale, économie de la santé: les choix implicites. Annales des mines. 74-80, 1991.

MOONEY, G. Economics of medicine and health care. Reino Unido, The Harvester Press Group, 1986.

PORTO, S.M. Descentralização de recursos no setor saúde. Comentários sobre algumas propostas. Planejamento e políticas publicas, 5:123-40, 1991.

QUEIROZ, M.S. Estratégias de consumo em saúde entre famílias trabalhadoras. Cad. Saúde Publ. 9(3):272-82, 1993.

QUEIROZ, M.S In: Representações sobre saúde e doença. Campinas, Editora da Unicamp, 1991.

SIMOM, J.M.; BERTRAND, D. Microeconomie. In: Elements de base en economie. Paris, Université Paris VII, 1992.

SINGER, P.; CAMPOS, O.; OLIVEIRA, E.M. Prevenir e curar: O controle social através dos serviços de saúde. Forense-Universitária, 1988. 
TRIOMPHE A. Economie Medicale. Paris, Heures de France, 1975.

VIANA, S.M. Saúde no Brasil. In: Saúde e Economia. Brasilia Cadernos da UNB, 1974.

VIANA, S.M.; ROMEU, N.; CASTRO, C.M. A mão invisível nos serviços de saúde: será que ela cura? In: XVI Reunião Do Conselho das Organizações de Ciências Médicas. Ibadan, 1982.

WORLD DEVELOPMENT REPORT 1993. Investing in Health. World Bank, Oxford University Press, 1993.

ZUCCHI,P. Gastos em saúde: Os fatores que agem na demanda e na oferta dos serviços de saúde. São Paulo, 1996. [Dissertação de Mestrado - Fundação Getúlio Vargas]

ZUCCHI, P.; DEL NERO, C.; MALIK, A.M.. Gastos em saúde: Os fatores que agem na demanda e na oferta dos serviços de saúde. Rev. Administ. Pública, 32(5):124-47, 1998.

\section{AGRADECIMENTOS}

Este trabalho só foi possível com a ajuda da Capes.

\section{HEALTH EXPENDITURES: DEMAND AND SUPPLLY FACTORS IN HEALTH SERVICES}

SUMMARY: In this moment of financial crisis of the State, it is important to adequately use the economic resources available. The objective of this survey is to study the factors that determine the increase in health expenditures. It is a critical review of the subject, conducting a systematic survey of publications for the past ten years, and considering the main scholars in health economics in Brazil and other countries. The health service demand factors have varied features, and may be overlapping, thus increasing even more the demand: the perceived need, social security, demography, epidemiology, the use of services, regulation, psychosocial and cultural factors. The health service supply factors are technical-medical progress, promotion of innovations and multiplication of health care centers. Demand factors cannot be quickly curbed, whereas the supply factors are more easily controlled. However, there are only a few examples in the literature on sucess of control measures.

KEY WORDS: financial crisis, health services, health expenditures, demand, supply 